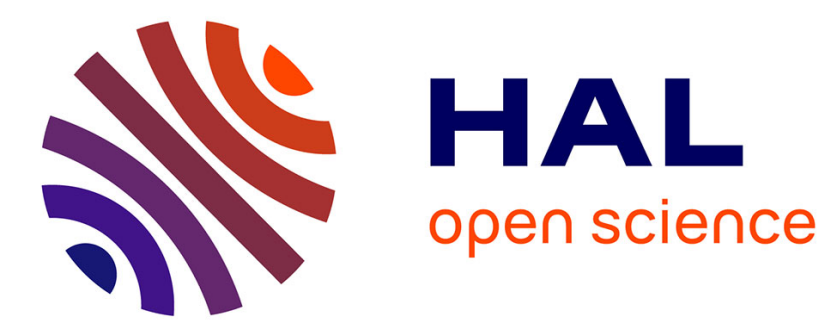

\title{
High Temperature Properties of TiCN-Mo2C-Co Cermets Studied by Mechanical Spectroscopy
}

\author{
G. Feusier, Thierry Cutard, C. Verdon, T. Viatte, W. Benoit
}

\section{To cite this version:}

G. Feusier, Thierry Cutard, C. Verdon, T. Viatte, W. Benoit. High Temperature Properties of TiCNMo2C-Co Cermets Studied by Mechanical Spectroscopy. Journal de Physique IV Proceedings, 1996, 06 (C8), pp.C8-751-C8-754. 10.1051/jp4:19968163 . jpa-00254598

\section{HAL Id: jpa-00254598 https://hal.science/jpa-00254598}

Submitted on 1 Jan 1996

HAL is a multi-disciplinary open access archive for the deposit and dissemination of scientific research documents, whether they are published or not. The documents may come from teaching and research institutions in France or abroad, or from public or private research centers.
L'archive ouverte pluridisciplinaire HAL, est destinée au dépôt et à la diffusion de documents scientifiques de niveau recherche, publiés ou non, émanant des établissements d'enseignement et de recherche français ou étrangers, des laboratoires publics ou privés. 


\title{
High Temperature Properties of TiCN-Mo $\mathrm{M}_{2} \mathrm{C}-\mathrm{Co}$ Cermets Studied by Mechanical Spectroscopy
}

\author{
G. Feusier, T. Cutard, C. Verdon, T. Viatte* and W. Benoit \\ Ecole Polytechnique Fédérale de Lausanne, Département de Physique, Institut de Génie Atomique, \\ 1015 Lausanne, Switzerland \\ * Stellram S.A., Rte de L'Etraz, 1260 Nyon, Switzerland
}

\begin{abstract}
Low frequency internal friction measurements were performed on $\mathrm{TiC}_{0.7} \mathrm{~N}_{0.3}-\mathrm{Mo}_{2} \mathrm{C}$-Co cermets in an inverted torsion-pendulum working with forced oscillations.

A thermally activated high temperature background and three thermally activated peaks were observed in the internal friction spectra. Two peaks, which are stable during thermal treatments, appear (at $1 \mathrm{~Hz}$ ) at about $1050 \mathrm{~K}$ and $1200 \mathrm{~K}$ respectively. The third peak, appearing at about $950 \mathrm{~K}$, is only observed during the first heating of the as-received samples. In order to locate the relaxation phenomena, similar measurements were performed on carbide-carbonitride skeletons, in which the metallic binder phase was chemically removed. Complementary microstructural characterizations, performed by conventional TEM, allow one to identify the physical mechanisms responsible for the IF peaks and background.
\end{abstract}

\section{INTRODUCTION}

The conditions during modern machining are more and more severe. Thus it is important to improve the mechanical properties, such as the toughness and the resistance to elastic and plastic deformation at high temperature, of the materials used in the fabrication of cutting tools [1].

Well known hard materials, the WC-Co cemented carbides, have been studied by means of acoustical spectroscopy methods. The works of Ammann, Schaller and co-workers $[2,3]$ pointed out the role of the metallic binder phase, mainly composed of cobalt, in the high toughness of the WC-Co at intermediate temperature $(800 \mathrm{~K}$ to $1100 \mathrm{~K}$ ). At higher temperatures (above $1100 \mathrm{~K}$ ) the WC-Co becomes ductile [2] and so is not well suited for high speed machining. The crystalline structure of the embedded cobalt remains fcc at room temperature, with a large number of hexagonal close packed stacking faults. All dislocations are widely dissociated. When a sufficient temperature is reached, the less stable stacking faults shrink to yield perfect dislocations, which can then give rise to relaxation processes. This property helps to improve the toughness of the material.

Other hard materials used successfully for cutting tool applications are the $\mathrm{TiC}_{07} \mathrm{~N}_{03}-\mathrm{Mo}_{2} \mathrm{C}-\mathrm{Ni}$ cermets. Their resistance to elastic and plastic deformation at high temperature is good [1, 4], but they have a weak toughness at low temperature. Viatte et al. [5] pointed out that the high resistance to the deformation is mainly due to the carbide-carbonitride part of the cermets. On the other hand, the martensitic phase transformation (hc $<->\mathrm{fcc}$ ) of pure cobalt [6] does not exist in nickel.

The purpose of the present work is to investigate the properties of materials which combine the binder phase of WC-Co and the hard phase of Ti(C,N) based cermets.

\section{EXPERIMENTAL}

$\mathrm{TiC}_{0.7} \mathrm{~N}_{0.3}-\mathrm{Mo}_{2} \mathrm{C}$-Co specimens were supplied by Stellram SA Nyon. The samples were fabricated by a conventional sintering process. The obtained plates were then straightened by hot-pressing during an annealing treatment at $1600 \mathrm{~K}$ and then quickly cooled to room temperature. Flat bars of $60 \times 4 \times 1 \mathrm{~mm}^{3}$ were finally cut by spark erosion.

A high temperature inverted subresonant torsional pendulum has been developed to perform the measurements as a function of frequency, under isothermal condition, or as a function of temperature, at a fixed frequency. The strain ranges from $10^{-6}$ to $10^{-5}$ at frequencies varying from about $10^{-4}$ to $10 \mathrm{~Hz}$. The 
temperature ranges from room temperature up to $1800 \mathrm{~K}$. The whole apparatus is maintained under a $10^{5}$ mbar vacuum.

\section{RESULTS}

\subsection{Characterization}

Figure la shows the microstructure of a cermet. The hard phase grains ( $\gamma$-skeleton) are composed of two parts, a core of $\operatorname{Ti}(\mathrm{C}, \mathrm{N})$ surrounded by a rim of $(\mathrm{Ti}, \mathrm{Mo}) \mathrm{C}$. The hard phase grains are embedded in a continuous metallic binder composed mainly of Co with atoms of Mo and Ti in solution ( $\beta$-phase).

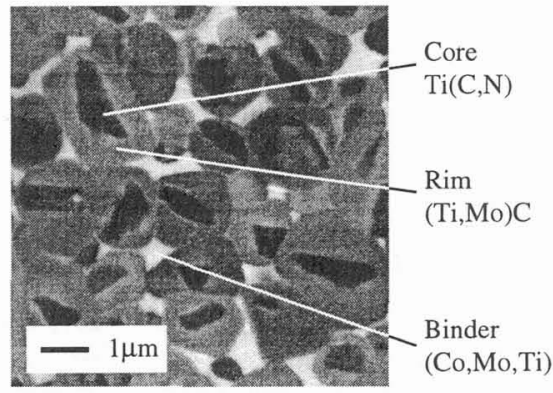

a)

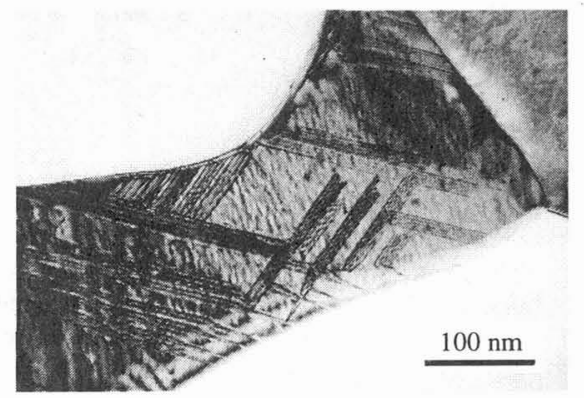

b)

Figure 1 : Micrographs of a $\mathrm{TiC}_{0.7} \mathrm{~N}_{0.3}-6.4 \% \mathrm{Mo}_{2} \mathrm{C}-6.4 \%$ Co (vol. \%) cermet. The picture a) shows the whole structure by means of SEM, and the picture b) shows the presence of stacking faults in the binder phase by means of TEM.

The typical IF versus temperature curve of the first heating of an as-received sample is shown in Figure 2a. On the same figure, the first heating is compared to the second heating after an annealing at $1400 \mathrm{~K}$ in the pendulum. During the first heating a mechanical loss peak $P_{0 \gamma}$ is observed at about $950 \mathrm{~K}$. This peak is no longer present during cooling and during the following temperature cycles.

Between $1150 \mathrm{~K}$ and $1200 \mathrm{~K}$, another mechanical loss peak $P_{2 \gamma}$ is observed during the first cycle as well as during all the following cycles. A medium temperature mechanical loss peak $\mathrm{P}_{1 \beta}$ appears at about $1050 \mathrm{~K}$ after the first annealing at $1400 \mathrm{~K}$ in the pendulum. This peak may already be present during the first heating, but masked by the presence of $\mathrm{P}_{0 \gamma}$. Thus, the annealing in the pendulum during the first heating seems to stabilize the sample. The subsequent measurements as a function of temperature only show slight alterations of the IF curves.

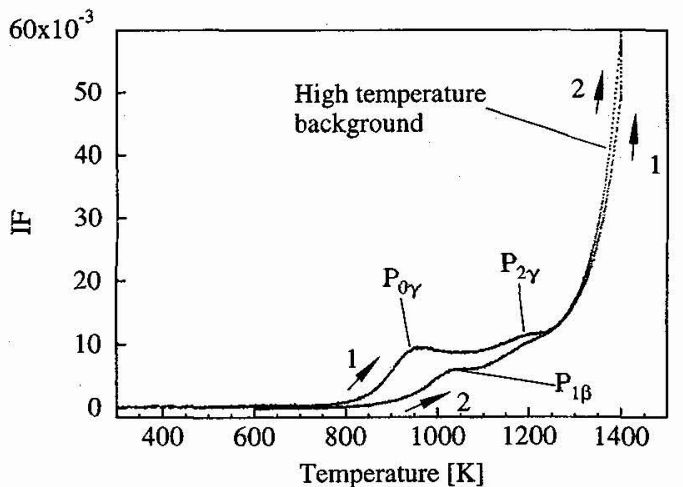

a)

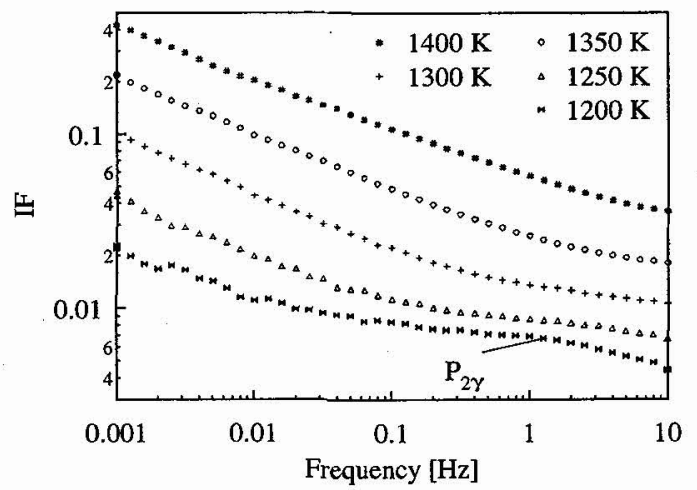

b)

Figure 2 : Experimental IF curves of a $\mathrm{TiC}_{0.7} \mathrm{~N}_{0.3}-6.4 \% \mathrm{Mo}_{2} \mathrm{C}-18 \% \mathrm{Co}$ (vol. \%) cermet. The picture a) shows IF vs. temperature curves $(1 \mathrm{~Hz}, 1 \mathrm{~K} / \mathrm{min}$ ) of (1) the first heating of an as-received sample and (2) the second heating. The picture b) shows IF vs. frequency curves at different temperatures.

Another important point, is the rise of the IF background at high temperature. A good approximation of the high temperature IF background measured here is an exponential form [7]. 
Isothermal measurements as a function of frequency were performed from $850 \mathrm{~K}$ to $1400 \mathrm{~K}$. The obtained frequency spectra, at temperatures between $1200 \mathrm{~K}$ and $1400 \mathrm{~K}$, are shown in Figure $2 \mathrm{~b}$. Two main components can be observed in these spectra. An exponential IF background at low frequency and a peak at higher frequency, corresponding to the $\mathrm{P}_{2 \gamma}$ peak observed during the temperature cycles at fixed frequency ( $P_{2 \gamma}$ appears at the same temperature and frequency in both types of measurements). As it can be seen, these two components are thermally activated. Similar measurements as a function of frequency were conducted at lower temperature and on as received samples in order to study the $P_{0 \gamma}$ and $P_{1 \beta}$ peaks.

After the subtraction of an exponential background, calculated by fitting the linear low frequency part of the spectrum in a $\log$-log representation, the obtained peaks are well fitted by enlarged Debye peaks [8]. The broadening of the peaks indicates that they are possibly not due to single point defect relaxations, but to the motion of larger defects with a distribution of relaxation times, for example, dislocations or grain boundaries [7]. The measured limit relaxation times, $1.4 \cdot 10^{-13} \mathrm{~s}$ for $P_{0 y}, 1.7 \cdot 10^{-9} \mathrm{~s}$ for $\mathrm{P}_{1 \beta}$ and $1.4 \cdot 10^{-10} \mathrm{~s}$ for $P_{2 \gamma}$ are in good agreement with the hypothesis of large scale defect relaxations to explain $P_{1 \beta}$ and $P_{2 \gamma}$

The apparent activation energies are calculated by means of Arrhenius plots of the frequencies of the peaks as a function of the temperatures. The values obtained for $P_{0 \gamma} P_{1 \beta}$ and $P_{2 \gamma}$ are $2.2 \mathrm{eV}, 1.5 \mathrm{eV}$ and $2.1 \mathrm{eV}$ respectively. The activation energy of the exponential IF background is $2.4 \mathrm{eV}$.

\subsection{Localization}

In order to locate the phases in which the relaxation phenomena take place, measurements were made on samples in which the metallic binder phase has been chemically removed.

To remove the metallic binder phase, the samples were maintained in a boiling $(\sim 366 \mathrm{~K}) \mathrm{HCl}+\mathrm{KClO}_{3}$ mixture for approximately $300 \mathrm{~h}$. The decrease of the cobalt content in the samples was controlled by means of weight loss and saturation magnetization measurements.

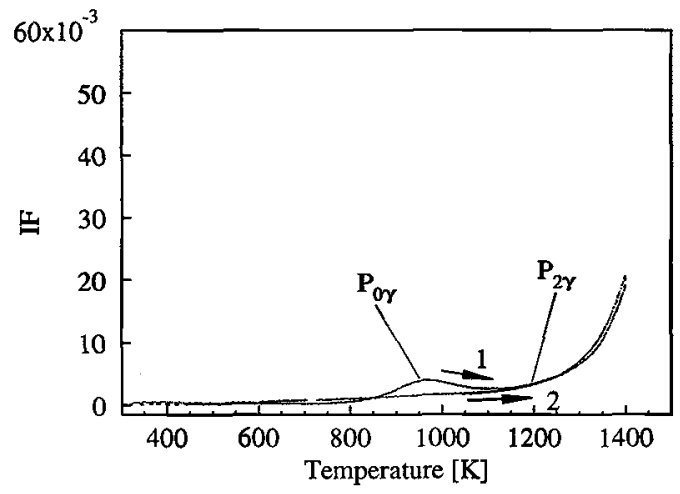

a)

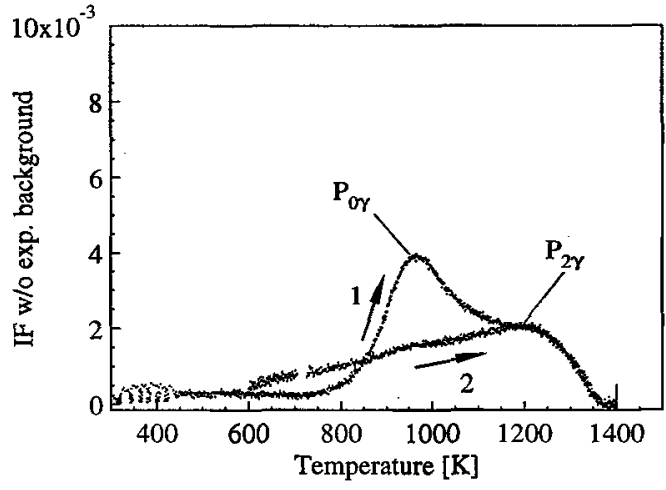

b)

Figure 3 : Experimental IF vs. temperature curves $(1 \mathrm{~Hz}, 1 \mathrm{~K} / \mathrm{min})$ of a $\mathrm{TiC}_{0.7} \mathrm{~N}_{0.3}-6.4 \% \mathrm{Mo}_{2} \mathrm{C}-18 \% \mathrm{Co}$ (vol. \%) cermet in which the metallic binder was chemically removed. The picture a) shows the first heating (1) of an as-received sample and the second heating (2). The picture b) shows the same measurements than picture a) after subtraction of the high temperature exponential IF background.

The IF measurements obtained during the first and second heatings of the chemically treated samples, called here the $\gamma$-skeleton, are given in Figure $3 a$ and $b$. The high temperature IF background is much lower than for the complete cermet, and the $P_{\text {or }}$ peak remains. The $P_{2 \gamma}$ peak also remains, but its amplitude is lowered. Its existence is also confirmed by measurements as a function of frequency.

Thus, it is possible to affirm that only $P_{1 \beta}$ and a part of the IF background are associated with the metallic binder phase. The $\mathrm{P}_{0 \gamma}$ and $\mathrm{P}_{2 \gamma}$ peaks should be associated with relaxation mechanisms in the hard phase $(\gamma$-phase) or at the grain boundaries.

\section{DISCUSSION}

A thin metallic binder film between the $\gamma$-phase grains, which appears during the liquid phase sintering, could be responsible of the presence of the $\mathrm{P}_{0 \gamma}$ peak. This peak could be associated with a local movement of the grain boundaries between the $\gamma$-phase grains. A restoring force is due to the elasticity of the $\gamma$-skeleton, limiting the movement of the $\gamma$-phase grains. A viscous force is due to the film of metallic binder, composed of cobalt alloyed with molybdenum and titanium. This thermally activated relaxation 
process is controlled by a diffusion process in the thin film layer. According to German [9], a thin film between grains exists because the equilibrium state is not reached during the fabrication of the samples. This film disappears during the subsequent high temperature measurements in the pendulum, leading to the disappearance of the $\mathrm{P}_{0,}$ peak. The existence and the vanishing of the thin metallic binder film has been observed by means of TEM.

The $P_{1 \beta}$ peak, associated with a relaxation mechanism located in the metallic binder phase, can be compared with the peak at about $920 \mathrm{~K}$ previously observed in WC-Co $[2,3]$, and in some part with the $P_{2 \beta}$ peak observed by Viatte et al. [5] in nickel cermets. In WC-Co, a similar peak was related to the relaxation of dislocation loops in cobalt after reduction of the stacking faults. In the present work, the existence and the reduction of stacking faults in the cobalt has been verified with TEM (Figure 1b) and insitu TEM (as a function of temperature) observations.

The $\mathrm{P}_{2 \gamma}$ peak can be related to a relaxation process of dislocations in the rims of the carbide-carbonitride grains. The existence of dislocations in the rim has been verified by means of TEM observations. The lowering of the amplitude of $P_{2 \gamma}$, when the metallic binder phase is removed, can be explained by a variation of the internal stresses due to the formation of porosity in the samples.

The IF peaks described here indicates the presence of local movements of defects. In this case, a restoring force always exists. When the restoring force disappears, due to the annihilation of the pinning points, the defects can move at long distances, producing irreversible creep of a thermally activated type. The corresponding IF background could then be given by an exponential form [7].

\section{CONCLUSIONS}

Several anelastic relaxation phenomena have been found in the $\mathrm{TiC}_{0.7} \mathrm{~N}_{0.3}-\mathrm{Mo}_{2} \mathrm{C}-\mathrm{Co}$ samples. Three peaks and an IF background associated with mechanisms located in the different phases of the cermets have been studied.

Compared to the WC-Co [2], the IF measurements performed here on $\mathrm{TiC}_{0.7} \mathrm{~N}_{0.3}-\mathrm{Mo}_{2} \mathrm{C}-\mathrm{Co}$ show that the temperatures of the IF components (peaks and background) of the cobalt binder cermets are shifted to higher temperatures. Moreover, the peak, due to the existence of recombined dislocations in the cobalt phase of the WC-Co, has also been observed in the $\mathrm{TiC}_{0.7} \mathrm{~N}_{0.3}-\mathrm{Mo}_{2} \mathrm{C}-\mathrm{Co}$.

Further measurements as a function of the composition are in progress which will help us to refine our understanding of the effects that determine the relaxation parameters. Finally, the IF results should also be correlated with the mechanical properties of the investigated materials.

\section{ACKNOWLEDGEMENTS}

Authors would like to thank Dr K.G. Stjernberg and Dr R. Schaller for helpful discussions. This work was supported by Stellram SA, Nyon (Switzerland), and by the Swiss "Commission pour l'Encouragement à la Recherche Scientifique".

\section{REFERENCES}

[1] Doi H., "Advanced TiC and TiC-TiN Base Cermets", Int. Conf. Sci. Hard Mater. 2, Rhodes 1984, E.A. Almond, C.A. Brookes and R. Warren Eds. (Inst. Phys. Conf. Ser. N.75, Adam Hilger Ltd, Bristol and Boston, 1986) pp. $489-523$.

[2] Schaller R., Mari D., Maamouri M., Ammann J.J., Journal of Hard Materials 3 (1992) 351-362.

[3] Ammann J.-J., Schaller R., Journal of Alloys and Compounds 211/212 (1994) 397-401.

[4] Cutard T., Viatte T., Feusier G., Benoit W., Materials Science and Engineering 1-2 (1996) 218-227.

[5] Viatte T., Cutard T., Feusier G., Benoit W. in this conference.

[6] Bidaux J.-E., Schaller R., Benoit W., Acta Metall. 37 (1989) 803-811.

[7] Nowick A.S., Berry B.S., Anelastic Relaxation in Crystalline Solids (Academic Press, New York, 1972).

[8] Fuoss R.M., Kirkwood J.G., Journal of the American Chemical Society 63 (1941) 385-394.

[9] German R.M., Liquid Phase Sintering (Plenum Press, New York, 1985). 